\title{
Egipto como Utopía: sobre el Busiris de Isócrates y su posible relación con el pensamiento político de Platón
}

\author{
David Hernández de la Fuente \\ Universidad Nacional de Educación a Distancia \\ dhdelafuente@geo.uned.es
}

Recibido: 9-10-2012

Aceptado: 20-12-2012

\begin{abstract}
RESUMEN
Durante los siglos v y Iv a.C., Egipto, el espejo conceptual en que se miraban los griegos al hablar de historia, ciencia o religión, estuvo muy presente en el debate acerca de la mejor forma de gobierno. El gobierno de los sabios o de los sacerdotes, dos de las ideas utópicas que arraigaron con fuerza en el pensamiento griego, encuentra en Egipto justificación mítica. Esta contribución pretende estudiar el discurso Busiris de Isócrates y sus posibles relaciones con los proyectos platónicos de la República y, sobre todo, las Leyes. Se analizará la imagen de Egipto como utopía y sus diversos enfoques en el contexto histórico-literario en torno a Isócrates y Platón, desde la ironía a la propuesta político-filosófica.
\end{abstract}

Palabras clave: Busiris, Isócrates, Platón, Las Leyes, Teoría política clásica, Utopía antigua

\begin{abstract}
During the 5th and 4th centuries BC, Egypt was a kind of conceptual mirror for the Greeks whenever they should speak of history, science or religion, and this is especially evident regarding the debate about the best form of government. The government of sages or priests, two of the utopian ideas most firmly rooted in Greek thought, finds a mythical basis in Egypt. This contribution aims to study the speech Busiris, by Isocrates, and its possible relationship with the Platonic projects of the Republic and, especially, the Laws. We will analyze the image of Egypt as an Utopian mirror and the various approaches to the historical and literary context of the relation bewteen Isocrates and Plato, from irony to political-philosophical proposals.
\end{abstract}

Keywords: Busiris, Isocrates, Plato, Laws, Classical Political Theory, Ancient Utopia

La versión tradicional de la leyenda del malvado rey egipcio Busiris la transmite el mitólogo Apolodoro en su resumen más ajustado (Biblioteca mitológica II, 5, 11):

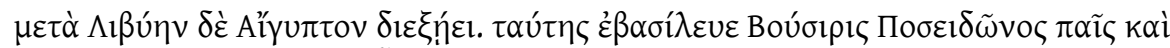

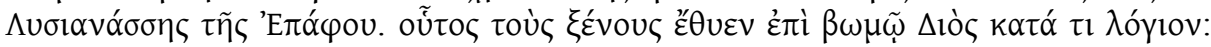

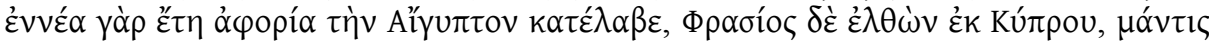

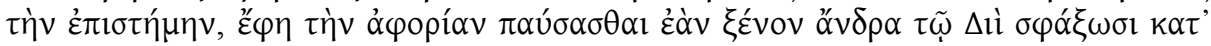




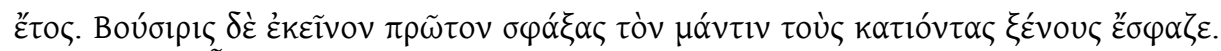

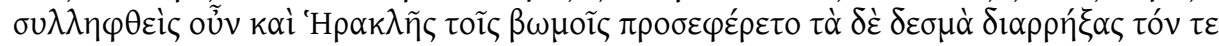

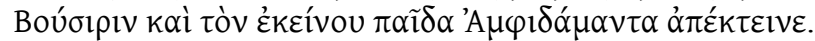

Después de Libia cruzó Egipto, donde reinaba Busiris, hijo de Posidón y Lisianasa, hija de Épafo. Busiris solía inmolar extranjeros en el ara de Zeus en cumplimiento de cierto oráculo: desde hacía nueve años la escasez afligía a Egipto, y Frasio, un adivino llegado de Chipre, había dicho que cesaría la esterilidad si cada año se sacrificaba un extranjero a Zeus. Busiris empezó por degollar al adivino y continuó con los extranjeros que llegaban. También Heracles fue apresado y llevado al altar, pero rompiendo las ligaduras dio muerte a Busiris y a su hijo Anfidamante. (trad. Rodríguez de Sepúlveda 1985)

En las fuentes Busiris aparece en principio como un legendario rey de Egipto de quien era fama que asesinaba a los griegos que llegaban a su país, en lo que suponía la más espantosa violación del sagrado vínculo de la hospitalidad y del respeto general a los huéspedes extranjeros. Sin embargo, en el primer cuarto del siglo IV a.C., el orador Isócrates le dedica un curioso discurso en el que la imagen de Busiris es muy diferente, pues aparece como un sabio legislador y benéfico hombre de gobierno. Algunos autores han señalado ya desde antiguo la importancia de este discurso en el contexto general de las utopías políticas y filosóficas de su época ${ }^{1}$. En todo caso, el Busiris de Isócrates es una buena excusa para examinar, siquiera brevemente, el espejo conceptual que supone el antiguo Egipto para la búsqueda griega en pos de la mejor legislación en el ambiente intelectual del siglo IV a.C.

Para Isócrates, Busiris ciertamente es todo lo contrario a ese malvado arquetípico que asesina a los huéspedes y al fin es vencido por el héroe de turno. Esa figura impía

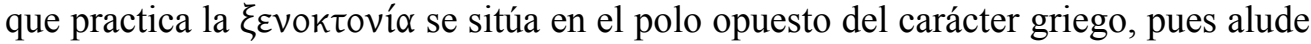
a un tabú solo comparable al crimen de sangre dentro de la propia familia o al incesto y de frecuente tratamiento en la tragedia ${ }^{2}$ : mitos como los de Enómao o Licurgo y tragedias como la Hécuba de Eurípides son buena muestra de ello. De hecho, el propio Isócrates en su Panatenaico (121-122) contrapone el buen gobierno ateniense a los grandes crímenes cometidos en otras ciudades «el asesinato de hermanos, padres, huéspedes...el matricidio y el incesto», que no en vano eran la materia prima para la tragedia griega, y estaban sobre todo presentes en las leyendas sobre la casa de Argos y la de Tebas.

En el Busiris de Isócrates, sin embargo, el rey egipcio es retratado como fundador de las instituciones políticas y religiosas de su Estado gracias a una legislación modélica cuyos principios fundamentales, como habremos de examinar en breve, no están lejos de los proyectos platónicos de la República, cosa que se ha puesto ya a menudo de relieve, y de las Leyes, en lo que pretende ser la aportación principal de este trabajo. Si nuestra hipótesis se confirmara, el Busiris isocrateo estaría muy cerca

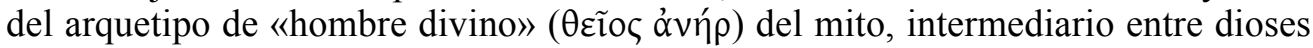

\footnotetext{
${ }^{1}$ P.e. el añejo estudio de Mathieu (1932). Últimamente destaca el exhaustivo comentario al Busiris por Livingstone (2001).

${ }^{2}$ Para la $\xi \varepsilon v o k \tau o v i ́ \alpha$, como definición de lo bárbaro frente a lo griego en la tragedia véase Belfiore (2000)
} 
y hombres, como modelo beneficioso de la mitología y, por ende, de los modelos de legisladores míticos sobre los cuales basa Platón su último proyecto político y filosófico en el comienzo de las Leyes.

Pero veamos brevemente las fuentes y testimonios de este episodio en orden cronológico. La fuente más antigua es un fragmento de Hesíodo sobre el personaje («hijo de Egipto» fr. 22 Rzach), y desde entonces hay muchas otras apariciones, casi siempre con matiz negativo ${ }^{3}$, que demuestran que Busiris ha sido ante todo

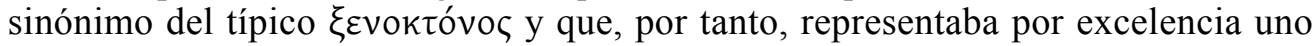
de los pecados capitales del mundo griego. Heracles se encarga de ajustar cuentas con este malvado asesino de huéspedes (como Pélope en el mito de Enómao) y de darle muerte en un episodio incluido entre los זó $\rho \varepsilon \rho \gamma \alpha$ del gran héroe griego que, sin embargo, a menudo ha tenido un tratamiento cómico. Es este momento de la muerte de Busiris a manos de Heracles el que constituye el «mitema» fundamental que refleja la iconografía, relacionada con el diverso tratamiento del tema en las fuentes literarias.

En los vasos áticos de figuras rojas puede constatarse una doble aproximación al tema de Busiris, insólita en los de figuras negras: una primera etapa arcaizante, más bien sombría, y otra más moderna con tonos jocosos que se aproxima a la comedia. Se puede asociar la mayor abundancia de escenas burlescas entre 540 y 440 a.C. según avanza el tiempo con el tratamiento del tema como asunto favorito de los comediógrafos a raíz de la ascensión de Heracles al Olimpo de la comedia. Esta progresión puede constatarse también en las figuras que ilustran la iconografía de Busiris al final del texto. Seguimos aquí el análisis que hace Papillon ${ }^{4}$ de la tradición iconográfica comparada con la literaria al hablar de dos aproximaciones al tema, una más bien siniestra y emparentada con el episodio trágico del asesinato de huéspedes y otra más cómica. Así, por un lado Ferécides (3 F 17 Jacoby), en un escolio a Apolonio Rodio, y Heródoto, refieren la versión tradicional y quizá más trágica (véase figura 2). Pero a comienzos del s. v a.C., por otro, Epicarmo dedica al mito una comedia titulada Busiris que contiene un retrato hilarante de Heracles, típico del género. Años después tenemos otra comedia también llamada Busiris y atribuida a Cratino (440-420 a.C.) y un fragmento papiráceo (POxy 3651), entre otros indicios, que señala la existencia de un drama satírico sobre este personaje escrito por Eurípides ${ }^{5}$. El asunto se convierte pronto, como puede verse, en tema predilecto de la comedia, una especie de «broma cultural», como muestra Papillon en su ponderado estudio (véanse figuras 1 y 3 ) $^{6}$. También hay noticia de otro grupo de comedias de Antífanes, Efipo y Mnesímaco fechadas entre 386 y 360 a.C., es decir, después de la datación tradicional del discurso de Isócrates, que muestra la pervivencia cómica del tema en el imaginario griego. Finalmente, en algunas variantes posteriores del mito se constatan ciertas evoluciones del

${ }^{3}$ Otras apariciones, aparte de las mencionadas, en Plutarco, Paral. 38, Virgilio, Georg. III 5, En. VIII 300 (y Servio, ad loc.), Higino 31, 2; 56; 157, 4; Ovidio, Ars Amandi I 647-652; Met. IX 182-183; Aulo Gelio, Noctes at. II 6, Macrobio, Sat. VI 7.

${ }^{4}$ Papillon (2001: 76-81).

${ }^{5}$ Jouan y Van Looy (2000: 37-44).

${ }^{6}$ Papillon (2001: 84). 
personaje. Busiris aparece como el patrón de los piratas enviados a raptar a las Hespérides (Diodoro Sículo IV 27) o como un glotón incorregible (Dión de Prusa VIII 32).

Pero veamos más en detalle la mencionada referencia en Heródoto (II 45), que alude al episodio de Busiris sin nombrarlo. Heródoto, buen conocedor de las antigüedades egipcias, niega que en el país del Nilo se hagan sacrificios humanos - y menos de huéspedes - poniendo en cuestión esta leyenda mediante una explicación racionalista:

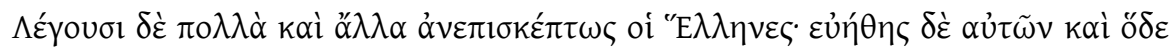

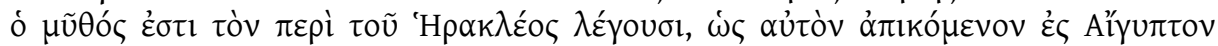

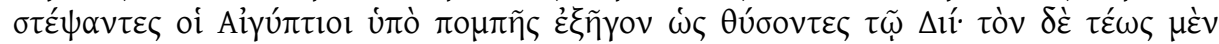

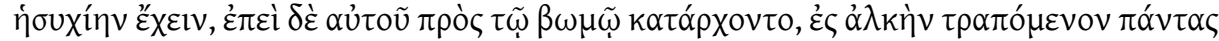

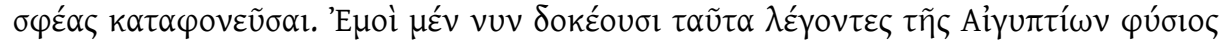

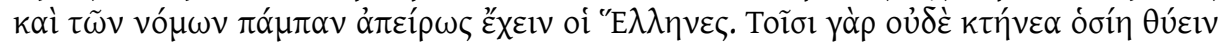

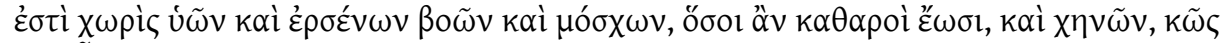

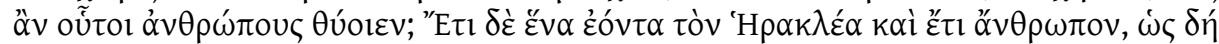

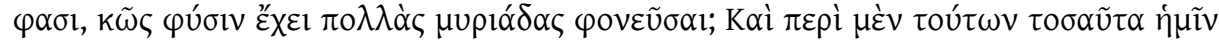

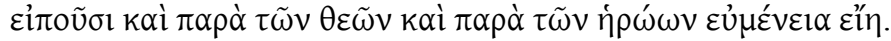

Entre las historias que nos refieren los griegos a modo de conseja, puedo contar aquella fábula simple y desatinada que en estos términos nos encajan: que los egipcios, apoderados de Hércules que por allí transitaba, le coronaron cual víctima sagrada, y le llevaban con grande pompa y solemnidad para que fuese a Júpiter inmolado, mientras él permanecía quieto y sosegado como un cordero, hasta que al ir a recibir el último golpe junto al altar, usando el valiente de todo su brío y denuedo, pasó a cuchillo toda aquella cohorte de extranjeros. Los que así se expresan, a mi entender, ignoran en verdad de todo punto lo que son los egipcios, y desconocen sus leyes y sus costumbres. Díganme, pues: ¿cómo los egipcios intentarían sacrificar una víctima humana cuando ni matar a los brutos mismos les permite su religión, exceptuando a los cerdos, gansos, bueyes o novillos, y aun éstos con prueba que debe preceder y seguridad de su pureza? (trad. Pou 1926)

En otro testimonio sobre el mito, Estrabón afirma que la historia se refiere a una ciudad poco hospitalaria llamada Busiris, pues no hubo ningún rey de tal nombre (XVII 802). De hecho, se puede hablar tres lugares en Egipto con este nombre: a la que se refiere Estrabón, y la más relevante en las fuentes griegas ${ }^{7}$, está situada en el delta del Nilo y es uno de los lugares míticos del nacimiento de Osiris ${ }^{8}$. Desde luego, el nombre de Busiris, que no aparece en ninguna lista de faraones, parece provenir del dios Osiris. Según Diodoro Sículo (I 17) significa «templo de Osiris» y parece que tal lugar era usado en la antigüedad para sacrificios humanos de extranjeros (I 88). Finalmente, Diodoro refiere una etimología griega del nombre contando una leyenda según la cual, cuando Isis recogió los miembros del despedazado Osiris, los puso en una vaca (ßô̂ৎ) de madera. De ahí provendría, pues, el nombre de la ciudad de Busiris,

\footnotetext{
${ }^{7}$ P.e. Heródoto I 59, 61,165. Plutarco, De Isis y Osiris 30.

${ }^{8}$ Otras son la necrópolis del Imperio Antiguo situada en las cercanías de El Cairo y Taposiris Magna, situada cerca de Alejandría.
} 
según una etimología popular griega «vaca de Osiris» (I 85) ${ }^{9}$, donde estaba situado el santuario más importante de la diosa Isis ${ }^{10}$.

En medio de todo este panorama de citas incompletas y alusiones dubitantes $-\mathrm{y}$ quizá siguiendo la línea pindárica y herodotea de corregir los mitos infundadosdestaca con voz propia el discurso Busiris de Isócrates. Se trata de una obra que se ha estudiado a menudo como ejemplo de encomio y artificio retórico, demostración de la habilidad sofística para redactar un discurso sobre temas supuestamente indefendibles, como la bondad de Helena o la del fiero ogro egipcio que retratan los mitos y los vasos antiguos bajo el nombre de Busiris. Supuestamente Isócrates está respondiendo con su obra al orador Polícrates, que había escrito de forma manifiestamente mejorable una Defensa de Busiris. Isócrates afea a Polícrates sus contradicciones compositivas y a continuación pasa a ocuparse del tema mostrándole a la vez cómo ha de hacerse un encomio de verdad (10-29), en la parte más importante de todo el discurso.

Sin embargo, y como veremos, Isócrates se aparta de las reglas que conocía para el encomio más usual e introduce temas de indudable raigambre filosófica en el contexto de la discusión sobre la utopía política que proporciona el mito egipcio, haciendo uso de la típica alusión a costumbres e instituciones extranjeras para hacer propuestas en cuanto a las propias. Detrás de todo el tema epidíctico subyacen, pues, algunas indudables referencias al debate político sobre la mejor constitución que pueden traslucir las posiciones del pensamiento político de Isócrates y su escuela en comparación con Platón. Para ello, se ha hecho de la datación una cuestión de suma importancia: la fecha tradicional en que se localiza el discurso, el 382-5 a.C., no permitiría en principio pensar que el Busiris tuviera influencia de la República de Platón (c. 375 a.C.). Por ello, autores como Wilamowitz han atribuido las ideas próximas a Platón que pueden notarse en este discurso a una supuesta influencia pitagórica ${ }^{11}$. No en vano, una de las referencias a Pitágoras más citadas por los estudiosos del pitagorismo antiguo se encuentra precisamente en este discurso isocrateo.

La recepción de esta obra de Isócrates ha sido, por lo demás, mayoritariamente negativa en la tradición, pues diversos autores han destacado la pobreza de su argumento $^{12} \mathrm{o}$ su falta de profundidad ${ }^{13}$. Pese a la opinión de quienes ven aquí un mero ejercicio escolar de vacuidad retórica, ha habido estudiosos que han defendido una contextualización filosófica de este discurso, como el estudio de Eucken en 1985 y, sobre todo, el comentario de Livingstone en 2001. En los últimos tiempos puede decirse que se ha rehabilitado la fama del Busiris y, sobre todo, su importancia en el debate de las utopías políticas en relación con Platón.

En cuanto a la estructura del discurso, se pueden establecer cuatro grandes secciones: la primera parte la ocupa un prólogo dirigido a Polícrates a la manera epistolar (1-9), a la que sigue una segunda parte que ejemplifica el modelo de encomio, expo-

${ }^{9}$ Falsa etimología, naturalmente. La primera que da Diodoro es en realidad la más verosímil (procede del egipcio pr 3sjr, «casa o templo de Osiris»). Mi agradecimiento al colega y amigo José Ramón Perez-Accino por sus aclaraciones al respecto.

${ }^{10} \mathrm{Cf}$. también Heródoto II 59.

${ }^{11}$ Wilamowitz (1959, II: 116, 3).

${ }^{12}$ Mathieu y Bremond (1929: 184).

${ }^{13}$ Froidefond (1971: 237). 
niendo de forma narrativa el linaje y hechos de Busiris (10-29); figura, a continuación, una tercera parte que incluye la apología propiamente dicha donde se argumentan las bondades del rey egipcio (30-43); finalmente, y en cuarto lugar, el discurso termina con un epílogo (44-50), en el que se incluye la preceptiva recapitulación retórica y la admonición final al destinatario de la obra.

Pero en lo que se refiere al contenido político y filosófico relevante para el modelo utópico y la comparación con Platón, hay que destacar en primer lugar los párrafos 15-16 de la mencionada segunda parte. Tras exponer la necesidad de encontrar un emplazamiento físico ideal para establecer el Estado, Isócrates atribuye al rey Busiris la ordenación del pueblo egipcio en un sistema tripartito de clases sociales o «castas», como algunos autores prefieren decir: sacerdotes, trabajadores y soldados.

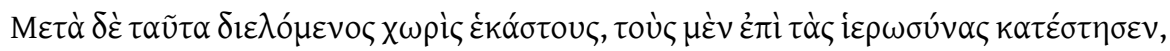

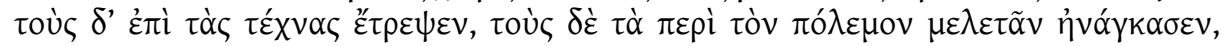

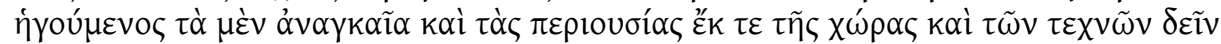

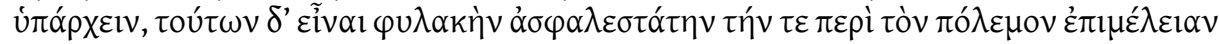

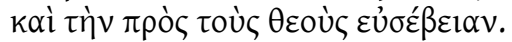

Tras esto, los dividió en clases, a unos los dedicó a actividades sacerdotales, a otros los orientó hacia las artes, a otros, en fin, los obligó a ocuparse de los asuntos bélicos, pues creía que había que extraer lo necesario y lo superfluo de la tierra y de las artes, y que la salvaguardia más segura es el cuidado de las cosas de la guerra y la piedad hacia los dioses (trad. Guzmán Hermida 1979).

Como precedente de esta aparición de Egipto como modelo social puede tomarse la mención a las castas egipcias como sistema de organización social que se encuentra ya en la descripción de Egipto por Heródoto (II 164), aunque en este autor tienen un número de siete. La reducción a tres, por tanto, ha sido objeto de frecuente discusión entre la crítica. Autores como Pohlenz, por ejemplo, han supuesto aquí una influencia directa de Platón y su tripartición de la República, aunque parece que ya Hipódamo (según Aristóteles, Pol. 1267 b 30ss.) establecía esta división. Para Livingstone, por su parte, hay que reseñar que también Aristóteles y Dicearco trataron este asunto ${ }^{14}$. Por otro lado, observamos que esta división responde a patrones de pensamiento que rigen a menudo en el pensamiento griego, tal vez procedentes de la tendencia a la tripartición profundamente enraizada en los pueblos indoeuropeos. Como en su momento analizó Georges Dumezil ${ }^{15}$, esta estructura tripartita se refiere a la función de administración de lo sagrado, la función del poder (físico, político) y la función productiva (la agricultura, la fecundidad). Es una idea que, siendo obviamente paralela a la de Platón, podría deberse a un contexto conceptual más genérico, si bien la coincidencia temporal y los indicios que a continuación se analizarán permiten afinar más certeramente esta valoración.

Más adelante, en el párrafo 16, se detalla más el contenido de la estratificación social de la presunta legislación de Busiris: las castas no pueden cambiar de profesión,

${ }^{14}$ Cf. Livingstone (2001: 133-35).

${ }^{15}$ En sus fundamentales estudios sobre la historia de las religiones indoeuropeas, cf. G. Dumézil (1941) [1999]. 
sino que la misma clase se ocupará siempre de las mismas funciones. Se da, pues, una separación estricta en la organización social y una especialización que, por otro lado, el propio Isócrates criticaba en Sobre la paz 54-55 al hablar de la realidad ateniense. Pero en el Busiris (16) se dice sobre el rey egipcio:

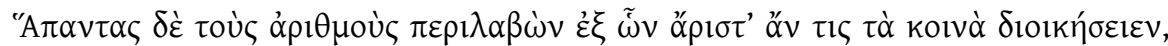

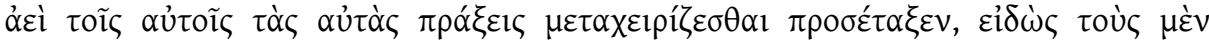

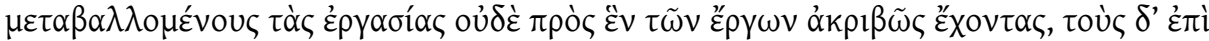

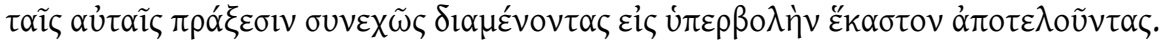

Habiendo hecho todos los cálculos con los que se puede gobernar de la mejor forma posible el estado, ordenó que siempre ejercieran las mismas actividades los mismos; pues sabía que los que cambian de ocupación no hacen con exactitud ni una sola cosa, mientras que los que sin interrupción se mantienen en las mismas actividades terminan cada una de ellas extraordinariamente bien (trad. Guzmán Hermida 1979).

La comparación con algunos pasajes del Platón político resulta muy reveladora, sobre todo en República 374 b ss., donde se afirma que cada profesión debería ser especializada y «cada hombre debería tener una ocupación, para la que ha sido dotado naturalmente y en la que ha de trabajar todos sus días». Por otro lado, la rígida estructura social que se describe en las Leyes (737 e), con un número cerrado de productores, ya propietarios de tierra ( $ү \varepsilon \omega \mu o ́ p o l)$ ya artesanos o comerciantes (846d-847a), junto a los guardianes y sacerdotes, viene a confirmar esta especialización de cada clase de ciudadanos en las ideas sociopolíticas del filósofo ateniense, que recuerda de cerca este retrato del utópico reino de Busiris. Ambos proyectos de Platón presentan, pues, un paralelismo con Isócrates en cuanto a las clases sociales y sus funciones especializadas y fijas.

El segundo aspecto de contenido que hay que analizar es la idea del gobierno ejercido por un ser semidivino, un sacerdote o un sabio anciano, también arraigada en la mentalidad griega. Para empezar, el propio dedicatario de este encomio isocrateo, Busiris, entra perfectamente en la categoría de legislador sagrado y de personaje excepcional, por su estirpe divina y su saber sobrehumano. La figura del legislador semidivino, que dota a la ciudad de las leyes del antiguo y buen orden de los dioses, aparece desde los inicios del pensamiento político griego y en sus relaciones con los personajes de «carisma» religioso, entendido a la manera de Max Weber en su sociología de la religión ${ }^{16}$, y está a menudo relacionada con el mundo egipcio. Las Leyes, por ejemplo, comienzan con una evocación de las constituciones divinas de la antigua Grecia por vía de los legisladores míticos de Creta y Esparta, con especial referencia a esta última ${ }^{17}$. Así sucede en el libro I de las Leyes con el legislador Licurgo de Esparta, cuya Constitución, junto a la de Creta, era de las más conocidas del mundo griego. El hecho de que el propio Isócrates, en su discurso Nicocles, aluda entre las mejores constituciones a la cartaginesa y la espartana, es muestra de que casi todas las investigaciones sobre la mejor ley en la literatura política griega hacían uso de tales modelos con prestigio

\footnotetext{
${ }^{16}$ Véase, por ejemplo, el estudio sociológico de Bryant (1986).

${ }^{17}$ Cf. en general Hernández de la Fuente (2010).
} 
de antigüedad y origen semidivino ${ }^{18}$. Según la tradición recogida por las Leyes (632d) Licurgo había recibido su legislación del oráculo de Apolo, con la visita del espartano a Delfos para obtener la famosa Retra ${ }^{19}$. En la opinión de muchos griegos las leyes espartanas eran las más antiguas de toda Grecia (Minos 320b-c), pero aparte de su procedencia divina se apreciaba su relación con un lugar originario del buen gobierno, que unas veces es Creta y otras el mítico Egipto. Parece que Licurgo, según esta versión, habría conocido esas leyes en la isla o en Egipto y luego las habría refrendado en Delfos ${ }^{20}$. Así se desprende, en cuanto a Egipto, de este pasaje de Isócrates.

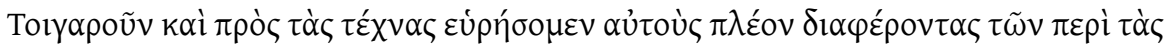

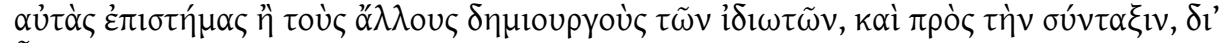

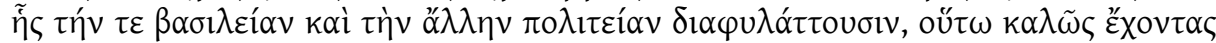

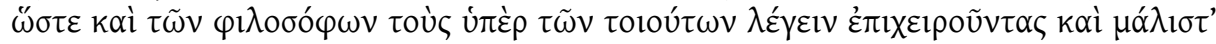

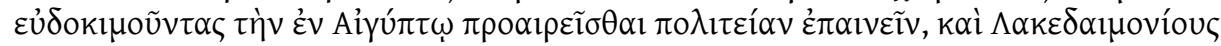

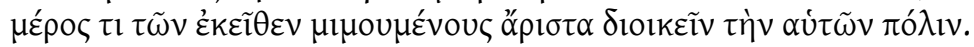

Por eso encontraremos que, en lo referente a las artes, los egipcios aventajan a los que se ocupan de las mismas ciencias más que los demás artesanos a los ignorantes; y es tan buena su organización, gracias a la que mantienen la realeza y otros elementos de su constitución política, que los filósofos dedicados a tratar de estos temas, y más reputados, han decidido alabar la constitución de Egipto, y los lacedemonios administran muy bien su ciudad porque han imitado algo de lo de allí (trad. Guzmán Hermida 1979).

El prestigioso origen egipcio de la legislación de Esparta, tan ponderada por autores como Jenofonte y otros partidarios del conservadurismo político y religioso, queda puesto de manifiesto por estas líneas de Isócrates. La Rhetra espartana posee a la vez el aura del modelo utópico egipcio y la sanción divina del oráculo de Delfos. En una clara contaminación de todas estas versiones, la Vida de Licurgo que redactó Plutarco (4-5) muchos siglos después refiere que el legislador que viajó a Creta para estudiar la forma de gobierno de la isla y traer de vuelta a su Esparta natal sus leyes divinas, pero también recoge la tradición de una estancia de Licurgo en Egipto. El pasaje en cuestión, que se hace eco de estas líneas isocrateas, afirma que Licurgo aprendió en Egipto la característica separación entre guerreros y trabajadores que se aplicaba en Esparta (en definitiva, la estructura social a la que alude Isócrates en el párrafo citado más arriba). Después de una y otra estancia para investigar la mejor legislación, Licurgo habría sometido finalmente sus leyes al refrendo sagrado del Apolo de Delfos, recabando del dios la constitución definitiva para Esparta.

Estos viajes de aprendizaje del legislador mítico a un lugar utópico y lejano donde aún reina la «buena y vieja ley», y sobre todo a Egipto, son un rasgo que hay que seña-

${ }^{18}$ Aunque al principio de las Leyes puede haber dudas al respecto - por ejemplo, cuando el extranjero ateniense critica el exceso de militarismo dorio - nos parece que el juicio al que se someten las constituciones divinas de Esparta y Creta deja al final un balance claramente positivo en el diálogo. Hay ejemplos en el Protágoras, donde la «filosofía» de espartanos y cretenses (342a ss.) y su sistema educativo es alabada, o, especialmente, la ponderación de sus gobiernos aristocráticos en República VIII 544 .

${ }^{19} \mathrm{Cf}$. también las referencias a este episodio en Heródoto I, 65, 2 y Diodoro VII, 12.

${ }^{20}$ Jenofonte, Const. de Esparta 1, 2; 7,5. Plutarco, Lic., 4-5. Cf. Morrow (1960: 33). 
lar y que está presente en algunos filósofos llamados «presocráticos» y en cuya faceta legisladora merece la pena insistir. Ocurre, en concreto, en el ámbito de la Magna Grecia y con figuras como Parménides, Zenón y, por supuesto, Pitágoras. Es imposible disociar este tema de la figura del legislador sagrado, un hombre divino y mediador, como Minos y Licurgo en las Leyes — ambos están inspirados desde el mundo de la mántica, el uno por la incubación en la cueva del Ida, el otro por el oráculo délfico ${ }^{21}$ o, por qué no, el propio Busiris en Isócrates, que destaca por su piedad y su contacto directo con lo divino para fundar la excelente legislación de su país.

Hay que recordar que en el mundo eleático tanto Parménides como Zenón legislaron y gobernaron para sus conciudadanos ${ }^{22}$ y que en otros lugares de la Magna Grecia se mencionan una serie de «hombres divinos», legisladores sagrados entre el mito y la historia de cronología bastante incierta pero sin duda relacionados con el pitagorismo. Uno de ellos es Zaleuco, precursor de legisladores y, alternativamente, alumno de Pitágoras o compañero en sus viajes de aprendizaje a Egipto. Según la Política de Aristóteles $^{23}$, Zaleuco dio las leyes a los Locrios Epicefirios, y para Platón se trata de uno de los pueblos mejor legislados entre los griegos (Timeo 20a ss. $)^{24}$. Otras figuras de este mundo de la legislación pitagórica, como Carondas de Catania, que habría legislado para su ciudad y para otras del ámbito de la Magna Grecia u Onomácrito que nació también entre los Locrios Epicefirios, también emprendieron viajes de aprendizaje a Creta o Egipto. Pero, sin lugar a dudas, la figura por excelencia del legislador de inspiración divina y mántica, viajero al mítico Egipto de la utopía, y fundador de reglas y preceptos universales es la del maestro de Samos, el propio Pitágoras. Isócrates le representa como el primero de los griegos en aprender, en este caso de Busiris (28), los preceptos y leyes divinas gracias a su pionero viaje a Egipto:

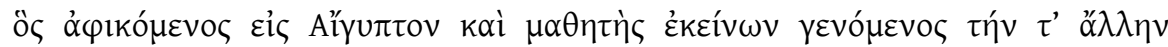

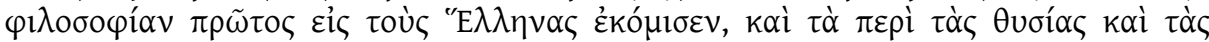

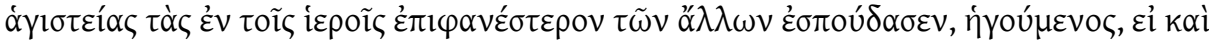

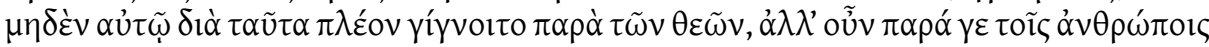

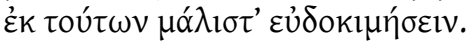

Este [scil. Pitágoras], después de llegar a Egipto y hacerse discípulo de aquellos hombres, fue el primero que llevó a los griegos una filosofía diferente y se aplicó con más brillantez que los demás en lo que se refiere a los sacrificios y ritos en los santuarios pensando que si por esto no obtenía más de los dioses, al menos gozaría con esto de la mayor reputación entre los hombres (trad. Guzmán Hermida 1979).

Claramente este pasaje muestra cómo se ha ido configurando a lo largo del tiempo un Egipto modélico, espejo de utopías, adonde acuden los sabios legisladores griegos del mito y de la política arcaica en una especie de viaje iniciático para aprender el arte

${ }^{21}$ Cf. Hernández de la Fuente (2010: 110-114).

${ }^{22}$ Diógenes Laercio IX 23.

${ }^{23}$ Aristóteles Pol. II 21, 1274a 22s.

${ }^{24}$ Platón escribe en ese mismo diálogo (22e ss.), en una paradoja que contrasta con todas estas tradiciones que conforman el trasfondo del Busiris, que fueron los egipcios los que imitaron las leyes de la antigua Atenas del mito. 
de hacer leyes que será preceptivo antes de emprender su labor. Egipto como espejo ideal en el que mirarse es referencia obligada incluso para los sabios legendarios de la tradición política griega, desde Solón y Licurgo hasta Pitágoras y sus comunidades de la Magna Grecia. Como dice Isócrates a las claras, la copia es evidente en los casos de Pitágoras y, sobre todo, de Esparta y su modelo de sociedad bélica. La excelente constitución egipcia es imitada por los espartanos, siguiendo la línea que localiza en Egipto el origen mítico de las constituciones divinas, y resulta en la especialización militar y obrera y en las comidas en común espartanas que tanta fama darán a la ciudad de Licurgo. Todo, según el texto de Isócrates, se lo debe Esparta paradójicamente a las leyes de Busiris ${ }^{25}$. Incluso, sostiene acto seguido, se trata de una mala imitación (Bus. 18-20), puesto que los espartanos son codiciosos, no como los sabios egipcios. La copia fracasa porque falta en los imitadores la parte religiosa y espiritual de los egipcios, acaso más cercana al mundo pitagórico.

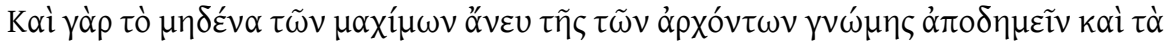

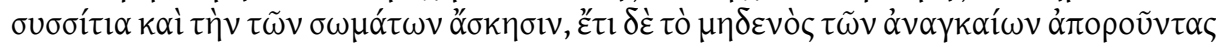

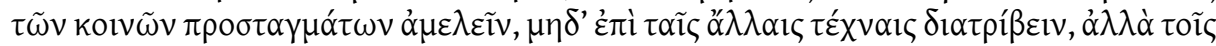

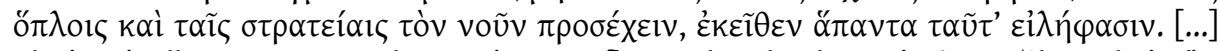

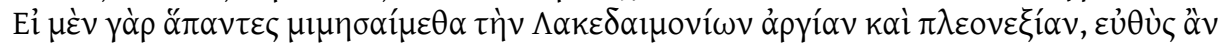

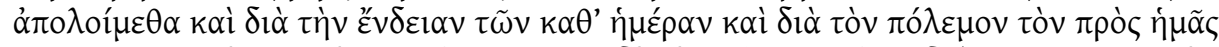

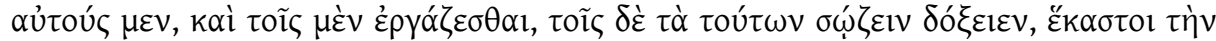

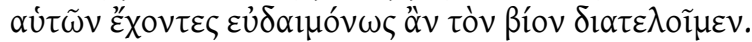

Pues el que ninguno de los guerreros [scil. espartanos] pueda salir del país sin permiso de sus jefes, las comidas públicas y el ejercicio físico, y además que no descuiden los preceptos estatales por carecer de lo necesario, ni se preocupen en otras actividades, sino que pongan su atención en las armas y en las expediciones militares, todo esto lo han tomado de allí [...] Si todos imitáramos la pereza y ambición de los lacedemonios, pereceríamos de inmediato, tanto por la falta del sustento cotidiano como por la guerra entre nosotros; en cambio, si quisiéramos servirnos de las leyes de los egipcios y quisieran unos trabajar y otros defender lo de éstos, unos y otros viviríamos felizmente con lo propio (trad. Guzmán Hermida 1979).

Como se ve, el mundo egipcio es una utopía que se refiere no sólo a aspectos materiales, sino también a bienes espirituales. Isócrates muestra una curiosa insistencia en los aspectos religiosos: por un lado, los que aprende Pitágoras para consagrarse luego en el mundo griego como maestro indiscutible de los asuntos divinos; por otro, la piedad egipcia que les falta a los espartanos y que, a la postre, causa el fracaso de su mímesis política en comparación con su utópico modelo. La religión, en definitiva, parece ya indisociable de la excelencia en la legislación y cualquiera que desee seguir el modelo egipcio ha de partir de un conocimiento de lo divino. También encontramos otras curiosas reminiscencias a la piedad, que recuerdan al mundo pitagórico, en el respeto a los animales, que ya mencionara Heródoto en el pasaje citado. Cf. Bus. 26-27:

${ }^{25}$ El origen de las comidas en común, Aristóteles, Pol. 1329 a 40 ss. lo localiza en el sur de Italia. 


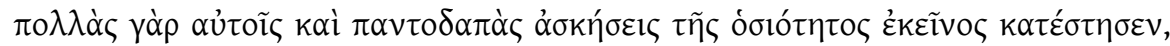

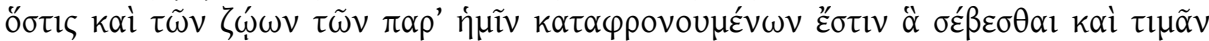

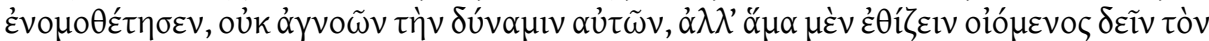

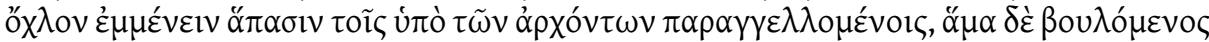

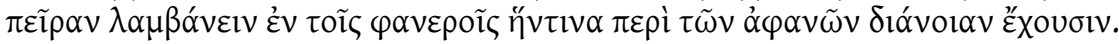

[Busiris] estableció para ellos numerosas y distintas prácticas de piedad, y mandó por ley que veneraran y honraran incluso a aquellos animales que entre nosotros se desprecian, no porque desconociese el valor de éstos, sino porque creía que había que acostumbrar a la masa a permanecer fiel a todo lo mandado por los gobernantes, y también porque quería captar en lo visible qué intención habían de tener con lo invisible (trad. Guzmán Hermida 1979).

Es precisamente este «mundo de lo invisible», el de la teología y la filosofía, el que más ha de preocupar al legislador que quiera imitar las perfectas leyes de este Egipto utópico. El Busiris de Isócrates impone a sus imitadores griegos un programa de estudios muy particular, centrado no solo en el conocimiento de lo divino, sino en filosofía pura, astronomía, geometría y matemáticas. El perfecto legislador egipcio ha procurado el bienestar del cuerpo y de la sociedad para obtener los bienes del espíritu en mayor grado, a través de la clase de los sacerdotes-filósofos. Y, como resulta evidente, este es el paralelo más llamativo con el pensamiento utópico de Platón, que ha hecho correr ríos de tinta ya desde antiguo (Bus. 21-22).

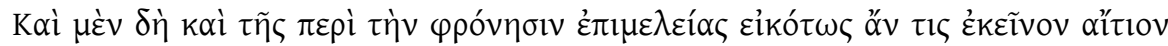

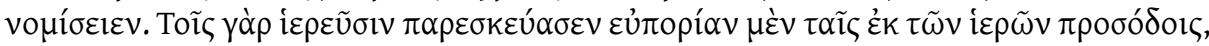

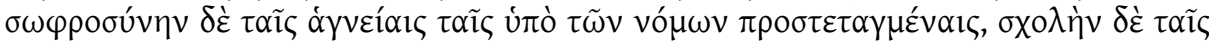

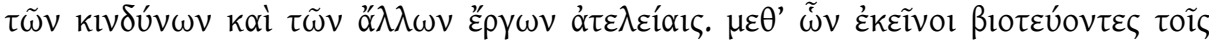

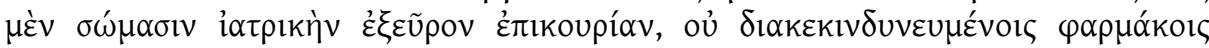

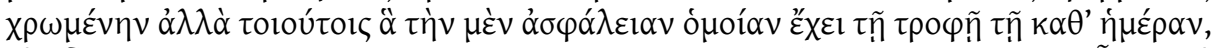

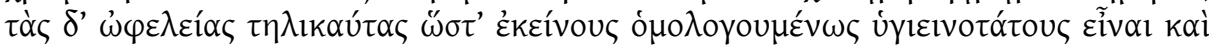

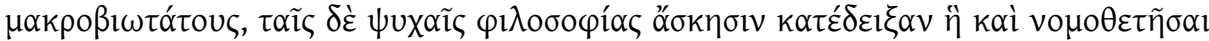

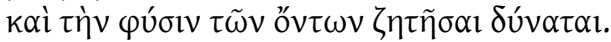

También se podría considerar a Busiris responsable del cuidado de la inteligencia. Pues proporcionó a los sacerdotes el bienestar con los ingresos de los santuarios, la prudencia con las purificaciones prescritas por las leyes y la tranquilidad con la exención de los riesgos bélicos y de otros trabajos; y al vivir con estas ayudas los sacerdotes descubrieron el auxilio de la medicina para los cuerpos, no la que se sirve de remedios arriesgados, sino de los que ofrecen una seguridad semejante al alimento de cada día, y tales ventajas que los egipcios, según reconocen todos, son los más sanos y longevos; para los espíritus dieron a conocer la práctica de la filosofía que puede establecer las leyes e investigar la naturaleza de los seres (trad. Guzmán Hermida 1979).

En este retablo hay también un eco del viejo Leitmotiv de la edad de oro y su longevidad proverbial, tal vez la utopía más exitosa de la mitología griega, pero también a los dos grandes programas político-filosóficos de Platón: la República y su ideal de filósofos-gobernantes y las Leyes y su programa educativo. Nótese que este curricu-

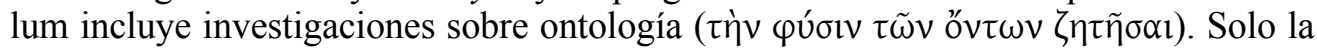


sabiduría divina y el programa de estudio filosófico permitirán que todos los ciudadanos alcancen esa utópica felicidad de la constitución ideal. Se trata de un programa educativo que tiene también claros nexos con el pitagorismo, como se esfuerzan por subrayar quienes defienden la independencia de Isócrates respecto de Platón. Pero hay que sostener, más bien, que Platón y el pitagorismo no son opuestos sino todo lo contrario: la educación mencionada es por excelencia pitagórica, como resaltan algunos autore ${ }^{26}$, pero hay abundantes referencias a este curriculum están igualmente presentes en Platón. El paralelo quizá más conocido con la República (522c ss.) es la instrucción prescrita en astronomía, matemáticas y geometría. Esta se complementa con la consideración hacia los ancianos, a los que se otorga un papel preponderante en la República (540 a-b), recordando igualmente a los ancianos que desempeñan las altas magistraturas de las Leyes y a los que rigen la educación de los coros dionisíacos en el libro II de este último diálogo platónico. En ese sentido, Isócrates escribe lo siguiente (Bus. 23):

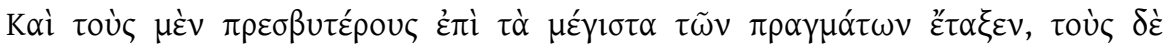

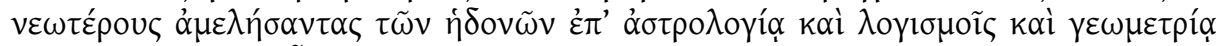

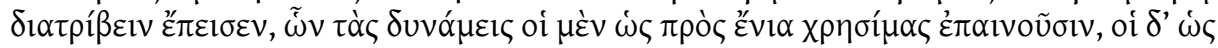

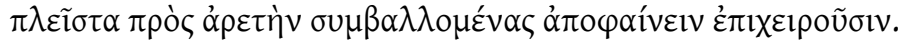

A los ancianos les encargó los asuntos más importantes y persuadió a los jóvenes a que dejaran los placeres y se aplicaran a la astrología, los cálculos y la geometría, habilidades que unos aplauden por ser útiles para algunas cosas y otros intentan demostrar que contribuyen muchísimo a la virtud de los egipcios (trad. Guzmán Hermida 1979).

A menudo se ha visto en esta alusión a los filósofos y su gobierno cierta intención paródica del estado platónico de la República ${ }^{27}$, que reflejaría el trasfondo de las discusiones teóricas sobre la mejor constitución en otros diálogos de Platón como el Timeo o el Critias. Todo depende, en primer lugar, de la lábil relación cronológica entre la obra platónica y este disputado discurso isocrateo, cuya fecha de composición se suele situar tradicionalmente en el año 382 a.C. Sin embargo, si seguimos la propuesta de datación de Eucken (1985), que rebaja la composición del Busiris a mediados de la década de 370 a.C, resulta más sencillo explicar esta aparente relación con el pensamiento platónico. Coincidirían ambas obras en una época marcada en Atenas por la vigencia de las ideas utópicas y comunistas - que se reflejan en la comedia, como en los ejemplos citados-, no tanto tiempo después de la representación, por ejemplo, de las Asambleistas de Aristófanes (c. 390 a.C.).

Sin embargo, la alusión isocratea refleja un trasfondo, más allá de la mera burla, que implica al orador en la discusión teórica. Egipto como utopía resultaba, así, un debate candente en este primer cuarto de siglo entre los teóricos de la política y la más clara referencia a ello es la mención de que «los filósofos dedicados a tratar de estos temas [scil. la política], y más reputados, han decidido alabar la constitución de

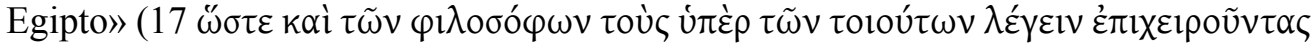

\footnotetext{
${ }^{26}$ P.e. Delatte (1922: 45), Froidefond (1971: 240 ss.).

${ }^{27}$ Cf. un estado de la cuestión en Livingstone (2001).
} 


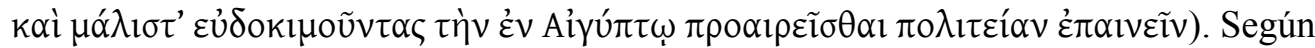
autores como Wilamowitz, esta alusión se refiere a algún teórico político pitagórico de épocas anteriores, pero hay muchos indicios ${ }^{28}$ que apuntan a un pensador contemporáneo: ¿quizá Platón? Así al menos lo han querido ver autores como Teichmüller, Gomperz y Pohlenz ${ }^{29}$. Lo cierto es que los pasajes citados del Busiris de Isócrates tienen demasiado en común con Platón para desdeñar esta idea: en concreto, se trata de aspectos tan conocidos de la teoría política platónica como las tres clases sociales, la división del trabajo, el gobierno de los sabios - filósofos, pero también sacerdotes, a juzgar por la preeminencia de lo relacionado con la mántica en las Leyes ${ }^{30}$-, la educación en principios filosóficos, matemáticos y astronómicos en el camino hacia la verdad y el bien, etc.

A veces se ha acusado a Isócrates de una asunción desprovista de críticas de estas visiones platónicas ${ }^{31}$, pero hay que aventurar que existen algunos aspectos seguramente propios del pensamiento isocrateo, que ponen de relieve la filosofía política del orador según se revela en otras obras suyas. Así, también se puede entender la figura de Busiris como paradigma mítico del rey en el marco de la preferencia por la forma de gobierno monárquica que puede notarse en otros discursos como los dedicados a Nicocles (6-8), en el que tal vez sea el primer espejo de príncipes de la literatura griega. Es obvio que Isócrates considera la monarquía como la mejor forma de gobierno en el debate político y utópico sobre la mejor constitución, anticipándose sin duda a los tiempos que habrían de venir y, en concreto, a la ascensión imparable de la monarquía macedonia. El Nicocles muestra, en paralelo con el Busiris, una sociedad rígida con una cúspide y una «igualdad geométrica», según expresión de Bringmann ${ }^{32}$. En el Nicocles, a la hora de afrontar el problema de la mejor legislación el elemento monárquico aparece como elemento básico, especialmente si en la cima hay un rey inspirado por una ley divina.

Creemos, por tanto, que es improcedente hablar de una parodia de Platón, sus ideas utópicas y su fascinación por Egipto en el Busiris de Isócrates. Sin duda, hay aquí, como se ha tratado de demostrar, a la vez un reflejo del prestigio de Egipto como lugar utópico y una afirmación explícita de la preeminencia de las antigüedades egipcias frente al pitagorismo y al subsiguiente platonismo, queriendo evidenciar todo lo que la República debe al saber divino de los egipcios, tal vez en el contexto de la rivalidad entre las escuelas de Platón e Isócrates ${ }^{33}$. En ese sentido, nuestra propuesta va más allá y postula una lectura de las Leyes como una suerte de última respuesta a este debate utópico en torno a Egipto y, por qué no, como una réplica al Busiris en la que, a gran distancia ya de cualquier polémica con Isócrates, Platón recoge el guante lanzado por este en su encomio de la legislación sacra y del hombre excepcional y subraya el valor

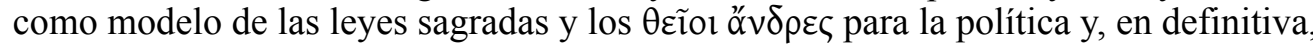
la validez de Egipto como utopía.

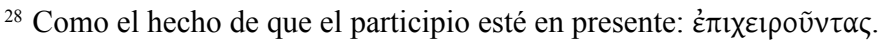

${ }^{29}$ Cf. un estado de la cuestión en Eucken (1983: 179).

${ }^{30}$ Cf. Hernández de la Fuente (2011).

${ }^{31}$ Gomperz (1905: 192 ss.).

32 Bringmann (1965: 105).

33 Teichmüller (1881, I: 166ss.).
} 
En efecto, al enmarcar la discusión sobre la legislación ideal de la ciudad de Magnesia con un discurso sobre los precursores míticos de la legislación divina, el extranjero ateniense que lleva el hilo argumentativo de las Leyes no sólo se remonta a los mencionados precedentes de Esparta y Creta, sino también a los santuarios y a la filosofia de los egipcios. Las leyes de un Egipto utópico se habían convertido, como se ha visto, en un modelo legendario para la comparación con Grecia, por su carácter sagrado e inmutable. A esto, huelga recordarlo, no era en absoluto ajeno Platón, como muestran las alusiones a asuntos egipcios en otros diálogos (Fedro 274c-275b, Filebo 19b...). En las Leyes, el legislador de Egipto deviene de nuevo modelo para la utopía, cuando se trata, por ejemplo, de las reglas que han de regir la creación artística y, en concreto, la música (656d-657b) ${ }^{34}$.

Como es ya sabido gracias a las lecciones del Busiris, la educación permanente del espíritu es lo que acaba concretando la utopía de la sociedad perfecta y en las Leyes

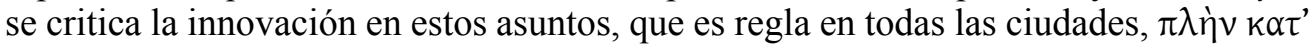

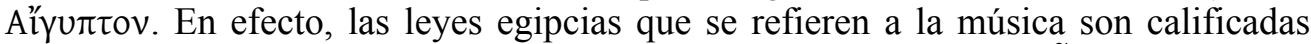

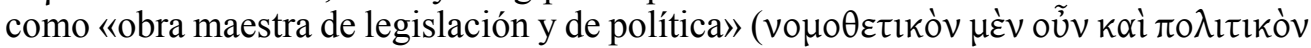

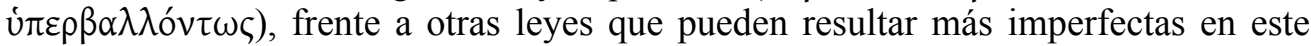
país, en lo que se torna una distancia crítica con la forja de un modelo utópico absoluto en el mito egipcio ${ }^{35}$. Para Platón, la preeminencia de las «viejas y buenas leyes», y su inmutabilidad, que garantiza la proximidad a lo divino, es el ideal al que hay que aspirar. Una perfección, en fin, que se pueden atribuir «solo a un dios o un hombre divino»

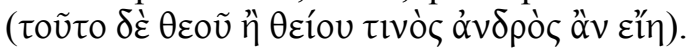

Tal vez este pasaje de las Leyes sobre Egipto y sus «hombres divinos» pueda leerse ahora a la luz del análisis anterior del Busiris de Isócrates e incluso entenderse como una última respuesta de Platón al debate en torno a la constitución perfecta: hay defectos, por supuesto, en las leyes egipcias. Platón no ve en ellas la perfección del elogio de Isócrates en el Busiris, de rasgos totalmente utópicos, salvo en cuanto a lo que es inmutable y validado por la inveterada tradición religiosa: en concreto, la poesía, la música, las artes. Especialmente relevante se nos antoja la relación del Busiris con las Leyes, último proyecto de Platón, que se puede fechar unos diez o quince años después de la República, para arrojar luz sobre el probable eco isocrateo de la República, mejor entendido como superación retórica que como parodia de la admiración platónica por Egipto. Si en las Leyes la presencia de la figura del legislador mítico como uno de estos fundadores inspirados por la divinidad que crean una comunidad perfecta se hace notar desde el primero al último libro del diálogo, el rey Busiris, tal y como lo retrata Isócrates, aparece como un perfecto ejemplo de tal figura semidivina. La figura mitológica de Busiris y su uso como modelo resulta muy provechosa, siguiendo los postulados de la ética política de la escuela isocratea. De hecho, la utilización de mitos como reserva de exempla para fines políticos en cada discurso es típico de la técnica oratoria de Isócrates ${ }^{36}$, que prefiere poner de relieve siempre los aspectos positivos de

\footnotetext{
${ }^{34}$ Cf. también $799 \mathrm{e}$.

${ }^{35}$ En ese sentido, hay que recordar de nuevo las indagaciones sobre la Atenas primordial y la relación de primacía con respecto a Egipto en el Timeo. Cf. nota 24.

${ }^{36}$ Bringmann (1965: 109).
} 
las leyendas tradicionales ${ }^{37}$. En el caso de Busiris no podía ser de otra manera, como se ha podido ver.

En definitiva, en el trasfondo, Egipto como utopía estaba presente en el debate cultural sobre la mejor constitución, como fuente inagotable de ideas políticas. En este sentido, todas las teorías que agitaban la Atenas de principios del siglo IV a.C., desde la comedia a la filosofía, del mito a la política y la iconografía, de los pitagóricos a Platón, se pueden justificar con alusiones a «cuentos egipcios» como el de Busiris. En todo caso, si algo refleja este discurso en comparación con las Leyes, a cuya relectura que estas notas pretenden invitar para un futuro trabajo más exhaustivo, es el papel de Egipto como espejo en el que se reflejaba la discusión filosófica y política en la escuela platónica e isocratea, en cuanto a las alusiones a un modelo de constitución divina regida más bien por $\theta \varepsilon \tilde{\imath} 0$ o ớv $\delta \rho \varepsilon \varsigma$ al viejo estilo del mito que por técnicos de la política.

\section{BIBLIOGRAFÍA}

Belfiore, Elizabeth S. (2000), Murder among Friends. Violation of Philia in Greek Tragedy. Nueva York-Oxford.

Bringmann, Klaus (1965), Studien zu den politischen Ideen des Isokrates. Göttingen.

Bryant, Joseph M. (1986), «Intellectuals and Religion in Ancient Greece: Notes on a Weberian Theme», The British Journal of Sociology, 37.2 (1986), 269-296.

Delatte, Armand (1922), Essai sur la politique pythagoricienne, Paris-Lieja, [reimpr. Ginebra 1979].

DumÉZIL, Georges (1941), Jupiter-Mars-Quirinus. Essai sur la conception Indo-Européenne de la société et sur les origines de Rome. París.

- [1999], Los dioses soberanos de los indoeuropeos, Barcelona [trad. esp. de Les dieux souverains des Indo-Européens, París 1977].

Eucken, Christoph (1983), Isokrates. Seine Positionen in der Auseinandersetzung mit den zeitgenössischen Philosophen, Berlín.

Froidefond, Christian (1971), Le mirage egyptien dans la litterature Grecque d'Homere a Aristote, Aix en Provence.

GOMPERZ, Heinrich (1905), «Isokrates und die Sokratik», Wiener Studien 27 (1905) 163-207.

Guzmán Hermida, Juan Manuel (ed. 1979), Isócrates. Discursos I. Madrid.

Hernández de la Fuente, David (2010), «Mythische Vorbilder des sakralen Gesetzgebers bei Platon (Nomoi I-IV). Eine Einführung in den religiösen Hintergrund der Nomoi», Zeitschrift für Religions- und Geistesgeschichte, 62.2 (2010) 105-124.

- (2011), «Oracles as Sources of Law and Plato's Reinterpretation of their Socio-political Role in the Laws», Journal of Hellenic Religion 4 (2011), 7-20.

Jouan, François y Herman Van Looy (eds. 2000), Euripide, Tragédies, vol. 8, $2^{\mathrm{e}}$ part. Fragments. De Bellérophon à Protésilas, París.

${ }^{37}$ Papillon (2001: 86). 
Livingstone, Niall A (2001), Commentary on Isocrates’Busiris. Mnemosyne Supplement 223. Leiden.

Mathieu, Georges (1932), «Les premiers conflits entre Platon et Isocrate et la date de l' Euthydème», Mélanges G. Glotz, París, II, págs. 555-564.

Mathieu, Georges y Emile Brémond (eds. 1929), Isocrate, Discours: Tome I (Collection Bude.). París [reimpr. 1963].

Morrow, Glenn R. (1960), Plato's Cretan City: A Historical Interpretation of the Laws. Princeton.

PAPILlon, Terry L. (2001), «Rhetoric, Art and Myth: Isocrates and Busiris», en C. Wooten (éd.), The Orator in Action and Theory in Greece and Rome, Leiden.

Pou, Bartolomé (ed. 1926): Herodoto de Halicarnaso. Los nueve libros de la historia. Traducción de Bartolomé Pou. [Madrid].

Rodríguez de Sepúlveda, Margarita (ed. 1985), Apolodoro. Biblioteca mitológica. Madrid.

TeIChmüLler, Gustav (1881), Literarische Fehden im vierten Jahrhundert vor Christi. 2 vols. Breslau [reimpr. Hildesheim 1978].

Wilamowitz-Moellendorff, Ulrich v. (1959), Platon. Sein Leben und seine Werke, 2 vols., 5. ed., Berlín. 


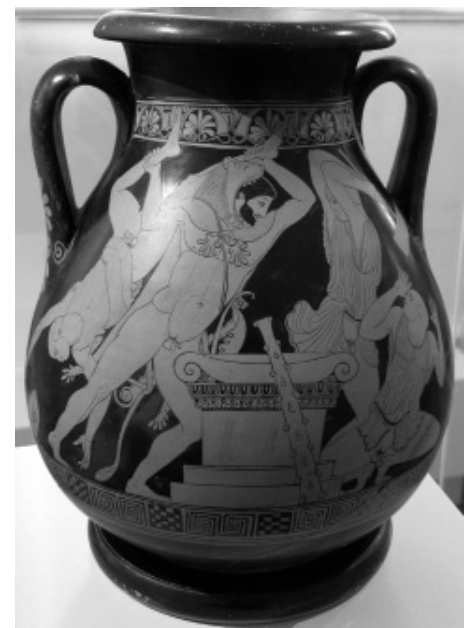

Fig. 1: Pelike de Figuras rojas c.480-460 a.C.

Pintor de Pan (Ethnikó Archaiologikó Museio Athinon, 9683).

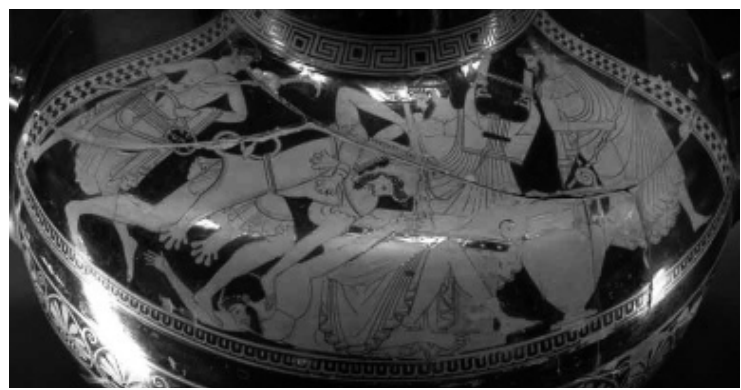

Fig.2: Hidria ática de figuras rojas, c. 490/80 BC. Pintor de Cleofrades (Musée du Louvre G50)

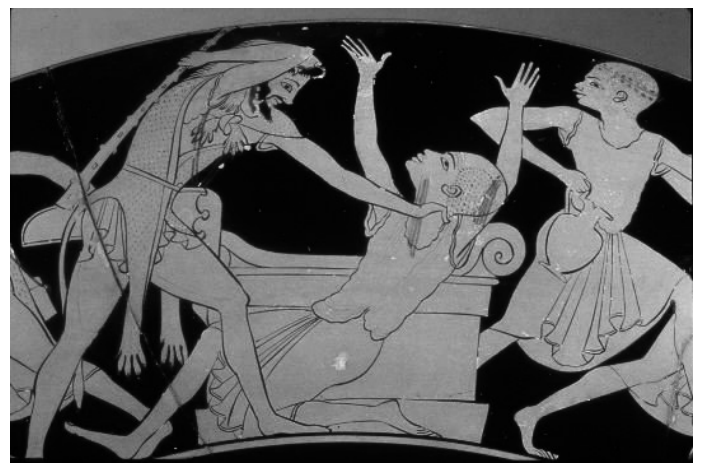

Fig 3. Detalle de un Kylix de figuras rojas procedente del Ática, c. 520-490 a.C.

(British Museum E38). 